\title{
Occupational Stress and Psychological Well-Being: The Role of Psychological Capital
}

\author{
Farah Shazlin Johari ${ }^{1}$, and Rosmini Omar ${ }^{2}$ \\ ${ }^{1}$ Faculty of Business and Management, Universiti Teknologi MARA, Malacca, Malaysia \\ ${ }^{2}$ International Business School, Universiti Teknologi Malaysia, Kuala Lumpur, Malaysia
}

\begin{abstract}
Occupational stress has become an important issue in many organizations, since it significantly results in unfavorable effects on both employees and businesses including infectious diseases, malpractice, creativity, productivity and economic loss. Even though, there were plethora of research confirm the negative effect of occupational stress on employees' psychological well-being, however, there were limited of research highlighted in the field of health care industry involving health care professionals. Furthermore, there is dearth of knowledge in the literatures focusing on mediating effect on these relationships, since there has been a rise of several interventions to strengthen the relationship between occupational stress and psychological well-being. Thus, this present study is intended to determine the relationship between occupational stress, psychological well-being and psychological capital. In addition, this study also intended to propose the role of psychological capital as mediator between these relationships. Since, the study is still at its infancy stage in the health care context, future research could integrate to expand this study especially in practical perspectives, to benefit both employees and organizations.
\end{abstract}

Key words: Occupational Stress, Psychological Well-Being, Psychological Capital, Health Care

\section{INTRODUCTION}

Globally, occupational stress has become an issue of great concern over the last decade. Stress is a major concern facing by many organizations, despite the increasing awareness of the impact of stress on business performance, however, the organizations was still unable to resolve this issue in the best possible ways [1].

Primarily, stress is referring to a particular relationship between a person and his or her environment that is appraised by the person as demanding or exceeding his or her resources and endangering his or her well-being [2].

Meanwhile, occupational stress is defined as the response people may have when presented with work demands and pressures that are not matched to their knowledge and abilities and which challenge their ability to cope [3].
Over the last three decades witnessed a progressively increasing concern of issue related to occupational stress resulting unfavorable effects on health and the consequent productivity, creativity and subsequent economic loss. Indeed, health care providers around the world are believed to be under pressure from sharp escalation of change, growing economic pressures, technological advances, increasing patient expectations, rationing of health care, and the requirement for more evidence-based and high quality health care, improved performance, and productivity [4].

Furthermore, occupational stress is becoming more important in health care industry due to several problems such as inadequate staffing, high public expectations, long work hours, exposure to infectious diseases and hazardous substances, threat of malpractice litigation and the constant encounters with death and dying.

Even, as reported in previous studies, it indicated that that healthcare workers were known as highly stressful group and were worryingly associated with higher rates of psychological distress than many 
other workers of different sectors [5]. Occupational stress among health care workers is an important concern due to its crucial contribution in attaining maximum job output and optimal quality of working life [6].

Recently, the studies on occupational stress were switching the focus on outcome such as psychological well-being. Psychological well-being is defined as the thriving for perfection that represents the realizations of one's true potential [7]. It means that people will have high levels of positive emotion and be satisfied with life in general. In addition, psychological well-being is referred to a state of well-being characterized by self-acceptance, purpose in life, environmental mastery, autonomy, personal growth and positive relations [8].

Thus, it is important to check stress levels and wellbeing status of health care professionals, as first and foremost they are directly involved with health care of the people. Any error arising out of stress could be hazardous to the patient if not life threatening [9]. Hence, although occupational stress and psychological well-being represents an important issue in every work environment, its importance is significantly higher in the field of medicine, as medicine is involved with critical decisions regarding public health [10].

\section{RATIONALE AND OBJECTIVES}

Even though, there were plethora of research which confirm the negative effect of occupational stress on employee health and their psychological well-being $[1,11,12,13,14,15]$ however, there is limited attention be highlighted in the field of health care industry involving health care professionals. Furthermore, the dimensions of occupational stress were applied differently in numerous studies especially in different context of studies.

Around the world, investigations have been widely conducted in the western societies but only limited studies have been documented among the Asian countries such Japan, China and Korea [16]. In addition, instead of focusing only on the relationship between occupational stress and psychological wellbeing among health care workers, it is suggested the intervention of mediating effect within these relationships in order to strengthen the overall outcomes of well-being. Furthermore, there is dearth of knowledge in the literatures on the mediator effect of psychological capital on this relationship, even though; there has been a raise in the number of intervention that mediates these relationships.

To fill the gap, the present study proposes the mediating effect of psychological capital on the relationship between occupational stress and psychological well-being among health care professionals. Thus, this present study is intended to identify and understand the potential mediating effect of psychological well-being among health professional in the health care context. Therefore, the research objectives for this paper are:

1. To determine the relationship between occupational stress, psychological capital and psychological well-being.

2. To investigate the mediating effect of psychological capital on the relationship between occupational stress and psychological well-being.

\section{LITERATURE REVIEWS}

\section{Occupational Stress and Psychological Well-Being}

According to previous studies, there were plethora of research which confirmed the negative effect of occupational stress on employee health and their psychological well-being [17, 18]. Accordingly, overall occupational stress was reported significantly negatively correlated with psychological well-being among female teacher in Pakistan [1]. The study conducted in United States confirmed that stress among African America female was negatively correlated with composited psychological well-being [14]. Furthermore, there was negative association between occupational stress and psychological well-being reported among manufacturing workers in China [15]. Meanwhile, in Malaysia, few studies conducted on occupational stress and psychological well-being among Administrative and Diplomatic Officer [11] and teacher [12] which both of studies confirmed that there were significant effects of occupational stress on psychological well-being.

Even though, as stipulated, numerous studies confirmed the associations between stress and wellbeing in different context, however, the unresolved occupational stress and psychological issues still alarming and should be addressed accordingly, since it will significantly affect both employees and organization in negative ways. In case, if these issues were not taken seriously, the occupational stress also results in low job satisfaction, psychological distress, poor mental and physical well-being, high absenteeism, turnover rate and intention to quit, accident and errors, and burnout among employees. Furthermore, evidence shows that occupational stress has a negative impact on employee job performance, and their physical and psychological well-being, including 
musculoskeletal and immune system complications $[19,20]$. All of these, consequently, impact on the overall functioning and profitability of organization [20]. Thus, this matter needs to be resolved immediately by taking several interventions to ensure the overall employees well-being meet the standards in performing better in the workplace.

\section{Dimensions of Occupational Stress and Psychological Well-Being}

Besides, there were different dimensions and measurement for occupational stress and psychological well-being were applied in several studies due to different setting and countries. These differences cause unpredictable result for overall outcomes of psychological well-being among workers. For instance, according to Ziyue et al., and Chang Yue et al., in 2017 [15], the studies adopted efforts, rewards and over commitment to represent the dimension of occupational stress. Both of the studies were conducted in China among Chinese cadres and manufacturing workers.

In different setting, like in India, dimension of occupational stress adopted including perception of job, work relationship, work-life balance, overload, job security, control, resources and communication, pay and benefit, and aspect of the job [13]. Meanwhile, in Malaysia, the difference dimensions of occupational stress were also adopted by the researchers due to difference respondent, context and industry. For instance, study conducted among teachers in Malaysia adopted source of stress and manifestation of stress as dimensions of occupational stress [12]. Whilst, study conducted among nurses in selected private hospitals in Malaysia were using workload, procedural injustice, role ambiguity, work-family conflict and physical environment as dimensions of occupational stress. It can be argued that several dimensions of stress overlapped with others. Thus, it is important to identify the best dimensions related to the context of the study. Accordingly, the present study tends to apply the Occupational Stress Inventory as part of dimensions of occupational stress in health care industry in Malaysia including role overload, role ambiguity, role conflict, unreasonable group and political pressure, responsibility for persons, under participation, powerlessness, peer group relations, intrinsic impoverishment, low status, strenuous working conditions, and unprofitability.

As compared to psychological well-being, most of the studies adopted dimensions for psychological well-being from Ryff and Keyes, 1995 [21] and Goldberg et al., 1998 [22] including autonomy, personal growth, environmental mastery, life purpose, self-acceptance, positive relatedness and general health.

Since, there is limited of studies using Occupational Stress Inventory as part of occupational stress dimensions in investigating the relationship with psychological well-being among health professionals in health care industry especially in Malaysia,

Most of the previous studies conducted mainly focused on teachers, manufacturing workers and government officers in education, manufacturing and government agencies. Hence, there is limited of studies on occupational stress and psychological well-being focused on health professionals in health care industry especially in Malaysia. Thus, preliminary actions need to be taken by researchers in addressing occupational stress accordingly in the relationship with psychological well-being for better workers' performance and organizational performance.

\begin{tabular}{|c|c|c|}
\hline Author(s) & Year & Mediator \\
\hline Ferlis, Tan \& Walton & 2016 & Social support \\
\hline Shazia & 2016 & Social support \\
\hline Ajay, Sabir \& Carry & 2013 & $\begin{array}{c}\text { Employee commitment; } \\
\text { Organizational commitment }\end{array}$ \\
\hline Yvonne & 2014 & $\begin{array}{c}\text { Coping behaviour; } \\
\text { Work motivation }\end{array}$ \\
\hline Mohd Dahlan et al. & 2009 & Coping behaviour \\
\hline
\end{tabular}

Table 1.1: Mediating factors influencing occupational stress and well-being 


\section{Psychological Capital}

According to Baron and Kenny in 1986 [23], suggested that a mediating role can be identified by using the following equations: (a) regressing the mediator on the independent variable, (b) regressing the dependent variable on the independent variable, and (c) regressing the dependent variable on both independent variables and on the mediator.

Thus, with increasing number of studies relating to occupational stress and psychological well-being, researchers should not only focus on independent and outcomes variables, but also intervention that mediates these relationships. As stipulated at Table 1.1, previous literatures reported several mediating factors influencing the relationship between occupational stress and psychological well-being as follows:

Recently, organizations reported may improve their employees' physical and mental health by enhancing their inner positive psychological resources [24]. Psychological capital has been demonstrated as a positive resource for improving employees' performance, job satisfaction, well-being, and for decreasing stress, turnover, and burnout [25, 26, 27, 28].

Generally, Psychological Capital is formally defined as positive psychological state of development characterized by four facets including self-efficacy, optimism, hope and resilience [26, 29]. Furthermore, Psychological Capital is recognized as a condition of positive psychological capacities that include selfefficacy, hope, optimism, and resilience, which can be measured, developed, and changed with various outcomes [30]. In other words, individuals with high Psychological Capital values can effectively deal with problems, anticipate good results, recover quickly from frustration, and confront negative situations with a better attitude.

However, as reported by previous studies, the mediating role of psychological capital was mainly to test the relationship between stress and job engagement [29], well-being and leadership, stress and leadership. Thus, it is needed to expand the mediating role of psychological capital in the relationship between stress and well-being especially in the health care setting.

Therefore, this present study adopts the psychological capital as a mediator to explain why some individuals can recover from difficulties better and are able to more easily build resources in the face of adversity. It is anticipated that psychological capital could also play the roles of recovery experiences and thus this study need to be expanded to include the role of psychological capital in influencing the relationship between occupational stress psychological well-being among health professionals in health care industry.

\section{CONCLUSION}

As a conclusion, this present paper has suggested psychological capital as a mediator that can potentially influence the relationship between occupational stress and psychological well-being among health professionals. Since, the study is still at its infancy stage in the health care context, future research could integrate to expand this study for both literatures and practical perspectives, since it can be beneficial for both employees and organizations in future.

\section{REFERENCES}

[1] Shazia K., (2016). Impact of Social Support on the Relationship between Stress and Wellbeing among Female Teachers in Pakistan. Retrieved fromhttp://eprints.utm.my/id/eprint/78984/1/Sh aziaKaziPFM2016.pdf

[2] Lazarus, R.S.; Folkman, S. Stress, Appraisal, and Coping (1984). Springer: New York, NY, USA.

[3] World Health Organization (2004) website (http:www.who.org).

[4] Reem A. M., Ebtisam M. A., Bibi M. A., Medhat K. E. \& Mohamed I. K. (2012). Sources and Expresiions of Stress among Physicians in a General Hospital. Alexandria Journal of Medicine, Vol. 48, pp. 361-366.

[5] Piko BF (2006). Burnout, role conflict, job satisfaction and psychological health among Hungarian health care staff: A questionnaire survey. Int. Journal of Nurse Studies, Vol. 43, pp. 311-318.

[6] Lua PL, Imilia I. (2011). Work-related Stress Among Healthcare Providers of Various Sector in Peninsular Malaysia. MJP Online Early.

[7] Ryff, C.D. (1995). "Psychological well-being in adult life", Current Directions in Psychological Science, Vol. 4 No. 4, pp. 99-104.

[8] Ryff, C.D. (1989). "Happiness is everything, or is it? Explorations on the meaning of psychological well-being", Journal of Personality and Social Psychology, Vol. 57 No. 6, pp. 1069-1081.

[9] Susmita H., Akash M. (2013). Stress and Psychological Well-Being Status Among Health Care Professionals. The International Journal of Occupational Health and Safety, Vol. 3(1), pp. 32-35.

[10] De Simone, S. (2015b). Expectancy value theory: Motivating healthcare workers. 
American International Journal of Contemporary Research, 5(2), 19-23. Retrieved from http://www.aijcrnet.com/journal/index/878

[11] Jasmani M. Y. \& Abdul J. M. (2011). Stress and Psychological Well-Being of Government Officers in Malaysia. The Journal of Human Resource and Adult Learning, Vol. 7 (2), pp. 4050.

[12] Ferlis B., Tan A. L. \& Walton W. (2016). The Effect of Occupational Stress on Teachers' Psychological Well-Being: Social Support as Moderator. Australian Journal of Basic and Applied Sciences, Vol. 10 (4), pp. 54-65.

[13] Ajay K. J., Sabir I. G. \& Cary L. C. (2013). Stress, Health and Well-Being: The Mediating Role of Employee and Organizational Commitment. International Journal of Environment Res. Public Health, Vol. 10, pp. 4907-4924.

[14] Yvonne N. G. (2014). African American Women, Psychological Well-Being, Religiosity and Stress. Retrieved from https://etd.ohiolink.edu/pg_10?0::NO:10:P10_A CCESSION_NUM:kent1416416324\#abstractfiles.

[15]Ziyue W., Hongbo L., Haijian Y., Yanwen W., Shuai C. \& Lie W. (2017). Associations between Occupational Stress, Burnout and Well-Being among Manufacturing Workers: Mediating Roles of Psychological Capital and Self-Esteem. BMC Psychiatry, Vol. 17, pp. 1-10.

[16] Li J., Yang W., Cho S. (2006). Gender Differences in Job Strain, Effort-Reward Imbalance, and Health Functioning among Chinese Physicians. Soc Sci Med. Vol. 62, pp. 1066-77.

[17] Akintayo, D.I., (2012). Occupational Stress, Psychological Well-Being and Workers' Behaviour in Manufacturing Industries in SouthWest Nigeria. Research Journal in Organizational Psychology \& Educational Studies, Vol. 1(5), pp. 289-294.

[18] Adegoke, T.G., (2014). Effects of Occupational Stress on Psychological Well-Being of Police Employees in Ibadan metropolis, Nigeria. African Research Review, Vol. 8(1), pp. 302320 .
[19] Wright, J. (2007). Stress in the workplace: A coaching approach. Work, 28, pp. 279-284.

[20] Sackey, J. and Sanda, M.A. (2009). Influence of occupational stress on the mental health of Ghanaian professional women. International Journal of Indian Ergonomic, 39, pp. 867-887.

[21] Ryff, C.D., C.L.M.Keyes, (1995). The structure of psychological well-being revisited. Journal of personality and social psychology, 69(4): 719.

[22] Goldberg, D. (1992) General Health Questionnaire (GHQ-12). Windsor: NFERNelson.

[23] Baron RM, Kenny DA (1986). The Moderator Mediator Variable Distinction in Social

Psychological Research: Conceptual, Strategic, and Statistical Considerations. J Pers. Soc. Psychol., Vol. 51(6), p. 1173.

[24] Lazarus RS, Folkman S. (1984). Stress, appraisal and coping. New York: Springer.

[25] Wang Y, Chang Y, Fu J, Wang L. (2012). Work-family conflict and burnout among Chinese female nurses: the mediating effect of psychological capital. BMC

Public Health, Vol. 12, p. 915.

[26] Luthans F, Avolio BJ, Avey JB, Norman SM. (2007). Positive psychological capital: measurement and relationship with performance and satisfaction. Pers. Psychol., Vol. 60, pp. 541-72.

[27] Rahimnia F, Mazidi AK, Mohammadzadeh Z. (2013). Emotional mediators of psychological capital on well-being: the role of stress, anxiety, and depression. Manage. Sci. Lett., Vol. 3, pp. 913-926.

[28] Avey JB, Luthans F, Jensen SM. (2009). Psychological capital: a positive resource for combating employee stress and turnover. Hum Resour Manag., Vol. 48, pp. 677-693.

[29] Hee-Yun Y., Hyun-Ju S., Yoonhyung C. JinHee K. (2017). Mediating Role of Psychological Capital in Relationship between Occupational Stress and Turnover Intention among Nurses at Veterans Administration Hospitals in Korea. Asian Nursing Research, Vol. 11, pp. 6-12.

[30] Luthans, F.; Luthans, K.W.; Luthans, B.C. (2004). Positive psychological capital: Beyond human and social capital. Bus. Horiz, 41, 45-50. 